\title{
Anticancer and apoptosis-inducing effects of quercetin in vitro and in vivo
}

\author{
MAHMOUD HASHEMZAEI ${ }^{1,2}$, AMIN DELARAMI FAR ${ }^{1,2}$, AREZOO YARI $^{1,2}$, \\ REZA ENTEZARI HERAVI ${ }^{2,3}$, KAVEH TABRIZIAN ${ }^{1,2}$, SEYED MOHAMMAD TAGHDISI ${ }^{4}$, \\ SARVENAZ EKHTIARI SADEGH ${ }^{1,2}$, KONSTANTINOS TSAROUHAS ${ }^{5}$, DIMITRIOS KOURETAS ${ }^{6}$, \\ GEORGE TZANAKAKIS $^{7}$, DRAGANA NIKITOVIC ${ }^{7}$, NIKITA YUREVICH ANISIMOV ${ }^{8}$, \\ DEMETRIOS A. SPANDIDOS ${ }^{9}$, ARISTIDES M. TSATSAKIS ${ }^{10}$ And RAMIN REZAEE ${ }^{11}$ \\ ${ }^{1}$ Department of Pharmacology and Toxicology, Faculty of Pharmacy, ${ }^{2}$ Students Research Committee, \\ School of Pharmacy, and ${ }^{3}$ Department of Pharmaceutical Biotechnology, Faculty of Pharmacy, \\ Zabol University of Medical Sciences, Zabol; ${ }^{4}$ Targeted Drug Delivery Research Center, School of Pharmacy, \\ Mashhad University of Medical Sciences, Mashhad, Iran; ${ }^{5}$ Department of Cardiology, Larissa University Hospital; \\ ${ }^{6}$ Department of Biochemistry and Biotechnology, Faculty of Animal Physiology-Toxicology, University of Thessaly, \\ Larissa; ${ }^{7}$ Department of Anatomy-Histology-Embryology, Medical School, University of Crete, Greece; \\ ${ }^{8}$ SEC Nanotechnology, Engineering School, Far Eastern Federal University, Vladivostok, Russia; \\ ${ }^{9}$ Laboratory of Clinical Virology, and ${ }^{10}$ Department of Forensic Sciences and Toxicology, \\ Faculty of Medicine, University of Crete, Heraklion, Greece; ${ }^{11}$ Clinical Research Unit, \\ Faculty of Medicine, Mashhad University of Medical Sciences, Mashhad, Iran
}

Received March 15, 2017; Accepted June 13, 2017

DOI: $10.3892 /$ or.2017.5766

\begin{abstract}
The present study focused on the elucidation of the putative anticancer potential of quercetin. The anticancer activity of quercetin at $10,20,40,80$ and $120 \mu \mathrm{M}$ was assessed in vitro by MMT assay in 9 tumor cell lines (colon carcinoma CT-26 cells, prostate adenocarcinoma LNCaP cells, human prostate PC 3 cells, pheocromocytoma $\mathrm{PC} 12$ cells, estrogen receptor-positive breast cancer MCF-7 cells, acute lymphoblastic leukemia MOLT-4 T-cells, human myeloma U266B1 cells, human lymphoid Raji cells and ovarian cancer $\mathrm{CHO}$ cells). Quercetin was found to induce the apoptosis of all the tested cancer cell lines at the utilized concentrations. Moreover, quercetin significantly induced the apoptosis of the CT-26,LNCaP,MOLT-4 and Raji cell lines, as compared to control group $(\mathrm{P}<0.001)$, as demonstrated by Annexin V/PI staining. In in vivo experiments, mice bearing MCF-7 and CT-26 tumors exhibited a significant reduction in tumor volume in the quercetin-treated group as compared to the control group $(\mathrm{P}<0.001)$. Taken together, quercetin, a naturally occurring compound, exhibits anticancer properties both in vivo and in vitro.
\end{abstract}

Correspondence to: Dr Ramin Rezaee, Clinical Research Unit, Faculty of Medicine, Mashhad University of Medical Sciences, Mashhad, Iran

E-mail: raminrezaee1983@gmail.com

Key words: quercetin, apoptosis, cytotoxicity, Annexin V/PI, cancer treatment, MTT assay

\section{Introduction}

The development or identification of compounds capable of killing transformed or cancer cells, without being toxic to their normal counterparts, is of utmost importance, and has gained the increasing interest of scientists worldwide. Since antiquity, plants have been considered rich sources of chemicals, with immense therapeutic potential. During recent years, some of these plant-derived compounds or phytochemicals have been shown to be highly competent anticancer agents, in addition to being effective against many other diseases (1-4).

Cancer, following cardiovascular diseases, is the main cause of mortality and morbidity in Europe. The key characteristics of this aggressive disease are uncontrolled growth and the spread of transformed cells (5). Each year, millions of individuals are diagnosed with cancer, whereas approximately 3.5 million cancer-related deaths are annually recorded worldwide $(6,7)$. Specifically, only in Europe, approximately 3.45 million new cases of cancer were reported in 2012, excluding non-melanoma skin cancer, whereas approximately 1.75 million deaths occurred (8).

Throughout history, plant extracts and their purified active components have been the backbone of cancer chemotherapeutics (9). It is estimated that over $70 \%$ of anticancer compounds are either natural products, or natural product-derived substances (10).

Natural polyphenols are a large and abundant group of phytochemicals found in herbal beverages and food (11-13). The plethora of these compounds is highlighted by the fact that up to date, over 8,000 polyphenols have been identified. 
Structurally, polyphenols consist of aromatic rings which are functionalized with one or more hydroxyl groups (12). Flavonoids and phenolics in particular, represent an important component of a normal human diet $(14,15)$. The average daily flavonoid intake varies from approximately $1-2 \mathrm{~g}$ per day (16), depending on the type and the amount of fruit, vegetables or beverages consumed. The existence of a negative correlation between a diet rich in polyphenols and various diseases, such as cancer, cardiovascular and degenerative diseases has been well established $(4,17)$. The total phenolic content (TPC) and the total flavonoid content (TFC) seem to correlate positively with in vivo and in vitro anticancer and antioxidant properties (18). Indeed, The American Institute of Cancer Research has reported that a high intake of fruit and vegetables correlates with a low risk of tumor occurrence (19). In addition, The National Academy of Sciences of the United States (1982) has also laid stress on the importance of fruits and vegetables in cancer prevention by including respective guidelines in its report on diet and cancer (20-22). The polyphenolic compounds have been reported to have many pharmacological activities, such as antioxidant, anti-inflammatory, anticarcinogenic, antiviral, or antiallergic effects (3,4,23-25).

Among anticancer and cancer preventing drugs, flavonoids are the most studied ones. These compounds can interfere with specific stages of the carcinogenic process, inhibit cell proliferation and induce apoptosis in several types of cancer cells (26-30). Flavonoids demonstrate a notable antioxidant activity, not only by inhibiting ROS generation, but also by affecting the activity of sundry detoxifying enzymes, such as cyclooxygenases, lipoxygenases and inducible nitric oxide synthase (3,31-33). This antioxidant capacity of flavonoids could possibly account for their anticancer potency. Flavonoids have also been found to influence epigenetic alterations by chromatin remodeling $(34,35)$.

Quercetin (3,3',4',5,7-pentahydroxyflavone) belongs to polyphenolic flavonoids which are abundantly found in apples, red grapes, onions, raspberries, honey, cherries, citrus fruits and green leafy vegetables, and exerts various biological effects, including antioxidant, anticancer, antiviral, apoptosis-inducing, protein kinase $\mathrm{C}$-inhibitory, cell cycle modulatory and angiogenesis inhibitory effects. Indeed, quercetin is a unique compound due to its potential to combat cancer-related diseases in a multi-targeted manner (36-38). A number of studies have investigated the anticancer activity of quercetin (39-41). In particular, it has been reported that quercetin at various concentrations, suppresses tumor growth of various cancer cell lines, including breast, colorectal, stomach, head and neck, lung, ovarian, melanoma and leukemia (42-50). In addition, quercetin has been shown to inhibit the release of P-glycoprotein in the MCF-7 cell line and to enhance in vitro anticancer activity of adriamycin in breast cancer cell line (44).

Furthermore, it has been suggested that the chronic administration and daily intake of quercetin may be useful for prevention of some cancer types (51). However, cancer treatment in many cases is not effective, with disease recurrence and/or spreading leading to poor outcomes (52). Thus, development of novel therapeutic strategies remains an important goal in the on-going battle against cancer.

The aim of this study was to investigate the anticancer effects of quercetin in vitro and in vivo. The in vitro experiments were performed using a cohort of 9 representative cell lines. We examined the effects of quercetin on cancer cell proliferation (using MTT assay) and apoptosis [utilizing flow cytometer Annexin V/propidium iodide (PI) and TUNEL assay]. In mice bearing MCF-7 and CT-26 xenografts, we also performed an in vivo evaluation of the effects of quercetin.

\section{Materials and methods}

Cell culture. We used the following cancer cell lines: CT-26 which is a mouse colon carcinoma cell line that is widely used for drug development (53); PC-12 cell line which is derived from pheocromocytoma and has been widely used as a model of neuronal differentiation (54); LNCaP (androgen-sensitive cancer line) and PC-3 (androgen-insensitive cancer line) utilized as prostate cancer models; MOLT-4 [the T-cell line that causes acute lymphoblastic leukemia (ALL)], U266B1 (human myeloma cell line) and the Raji cell line (derived from human lymphoid) utilized as blood cancer models; we also used MCF-7 cells (estrogen receptor-positive breast cancer cells) as a breast cancer cell model; and $\mathrm{CHO}$ (ovarian cancer cell line) utilized to study ovarian cancer responses. The cancer cell lines (Pasteur Institute, Tehran, Iran) were grown under the following conditions: the CT-26, MOLT-4, U266B and PC12 in RPMI-1640 (Sigma, St. Louis, MO, USA); the PC3 cells in Ham's F12 (Sigma) and the LNCaP, MCF-7, Raji and CHO cells in DMEM (Sigma) supplied with 10\% FBS (Gibco, Grand Island, NY, USA) and penicillin-streptomycin (Sigma) at $37^{\circ} \mathrm{C}$ in a humidified incubator containing $5 \% \mathrm{CO}_{2}$. All experiments were performed when the cells reached $85-90 \%$ confluence.

Measurement of cell viability by MTT assay. Dilution series $(10,20,40,80$ and $120 \mu \mathrm{M})$ of quercetin were prepared and used for 3-(4,5-dimethylthiazol-2-yl)-2,5-diphenyl tetrazolium bromide (MTT) assay. All 9 cancer cell lines were seeded at a density of $1.5 \times 10^{4}$ cells/well and treated with a range of concentrations in triplicate in 96-well cell culture plates, whereupon cell proliferation was assessed using a standard MTT assay. Specifically, the growth inhibitory activity of quercetin was determined using MTT, which correlates the cell number with the mitochondrial reduction of MTT to a blue formazan precipitate. In brief, the cells were plated in 96-well plates and allowed to attach overnight. The medium was then replaced with serum-free medium containing the test compounds and cells were incubated at $37^{\circ} \mathrm{C}$ for $72 \mathrm{~h}$. The medium was then replaced with fresh medium containing $1 \mathrm{mg} / \mathrm{ml}$ MTT. Following incubation at $37^{\circ} \mathrm{C}$ for $2-4 \mathrm{~h}$, the wells were aspirated, the dye was solubilized in DMSO and the absorbance was measured at $570 \mathrm{~nm}$ using a BioTek Instruments EL800 Microplate Reader (BioTek Instruments, Inc., Winooski, VT, USA). The viability of cells was compared with that of the control cells.

Detection of necrosis and apoptosis by flow cytometry. For the evaluation of apoptosis using the Annexin V/PI method, the LNCaP, CT-26, MOLT-4 and Raji cells were seeded in 12 -well plates $\left(2 \times 10^{5}\right.$ cells/well). The cells were cultured and incubated (with $5 \% \mathrm{CO}_{2}$ and $95 \%$ air) at $37^{\circ} \mathrm{C}$. Various concentrations of quercetin $(10,20,40,80$ and $120 \mu \mathrm{M}$ were dissolved 
in DMSO and incubated with the cells for $48 \mathrm{~h}$. DMSO in culture medium never exceeded $0.1 \%$ (v/v), the concentration known not to affect cell proliferation. The Annexin V-FITC/PI apoptosis kit (Abcam, Cambridge, MA, USA) was used. For this purpose, the cells were incubated with $5 \mu \mathrm{l}$ Annexin V-FITC and $5 \mu \mathrm{l}$ PI for $5 \mathrm{~min}$ in the dark. The treated cells were analyzed using a Partec PAS flow cytometer (Sysmex Partec GmbH, Gorlitz, Germany).

In vivo experiments. Female BALB/c mice, aged 6-8 weeks (weighing, 20-25 g) were obtained from Zabol University of Medical Sciences (Zabol, Iran). The animals were maintained in a temperature and humidity-controlled room. On day 1, the animals were shaved on the back flank. In the shaved right flank of each mouse, $3 \times 10^{5}$ CT-26 or MCF-7 cells in $50 \mu 1$ PBS were injected subcutaneously, as previously described (55). Eight days after tumor implantation, the animals were randomly assigned into 8 groups as follows (5 mice in each group): i) CT-26 tumor-bearing mice treated with dextrose 5\% (CT-26 control group); ii) CT-26 tumor-bearing mice treated with $50 \mathrm{mg} / \mathrm{kg}$ [intraperitoneally (i.p.)] quercetin; iii) CT-26 tumor-bearing mice treated with $100 \mathrm{mg} / \mathrm{kg}$ (i.p.) quercetin; iv) CT-26 tumor-bearing mice treated with $200 \mathrm{mg} / \mathrm{kg}$ (i.p.) quercetin; v) MCF-7 tumor-bearing mice treated with dextrose 5\% (MCF-7 control group); vi) MCF-7 tumor-bearing mice treated with $50 \mathrm{mg} / \mathrm{kg}$ (i.p.) quercetin; vii) MCF-7 tumor-bearing mice treated with $100 \mathrm{mg} / \mathrm{kg}$ (i.p.) quercetin; and viii) MCF-7 tumor-bearing mice treated with $200 \mathrm{mg} / \mathrm{kg}$ (i.p.) quercetin. The tumor volume was measured and calculated based on the following formula: [(length) $\mathrm{x}$ (width)2]/2, as previously described $(56,57)$.

In addition, the animal survival rate was evaluated up to 40 days. Furthermore, for apoptosis evaluation in the animals, terminal deoxynucleotidyl transferase-mediated dUTP nick-end labeling (TUNEL) assay was performed. The study protocol was approved by the Ethics Committee of Zabol University of Medical Sciences. All experimental procedures conformed to the declaration of Helsinki and were conducted in accordance with recent legislation of National Institutes of Health guide for the care and use of laboratory animals.

In situ apoptosis assay. Implanted tumor tissues were collected and apoptosis was detected using TUNEL assay. Based on the instructions of the manufacturer (Roche Diagnostics, Basel, Switzerland), paraformaldehyde-fixed blocks were embedded in paraffin, cut into 4- $\mu \mathrm{m}$ thick slices, and incubated with TUNEL reaction mixture containing TdT and fluorescein-dUTP. Prior to incubation of the slices with TUNEL mixture, their permeability was enhanced by proteinase solution. The TUNEL signal was then detected by an anti-fluorescein antibody conjugated with alkaline phosphatase (in situ Cell Death Detection kit; 11684809910 Roche; Sigma), a reporter enzyme, which catalytically generates a colored product. Three slides from each block and four slide fields were evaluated for the percentage of apoptotic cells. Four fields were randomly selectd on each slice and the number of apoptotic myocardial cells/total myocardial cells was calculated, at x200 magnification. At the end of this procedure, the apoptotic index (number of myocardial nuclei labeled by the TUNEL method/number of total myocardial nuclei) was calculated, as previously described (58).
Statistical analysis. Statistical analysis was performed using the Student's t-test. Data are presented as the means \pm standard deviation of 3 independent treatments. A value of $\mathrm{P}<0.05$ was considered to indicate a statistically significant difference.

\section{Results}

Cell viability. MTT assay was used to evaluate the viability of all 9 cancer cell lines following 24, 48 and $72 \mathrm{~h}$ of treatment with quercetin at 10, 20, 40, 80 and $120 \mu \mathrm{M}$ (Table I). All utilized concentrations of quercetin were inhibitory with the exception of the PC3 and CHO cells where at the $24 \mathrm{~h}$ time point, no inhibition was evident even at the highest concentration $(120 \mu \mathrm{M})$ as presented in Table II. Furthermore, MTT assay revealed that the inhibitory effect of each concentration of quercetin on the viability of all cancer cell lines was enhanced by an increase in the incubation time. In addition, we calculated the $\mathrm{IC}_{50}$ values as previously described by Entezari Heravi et al (59). Therefore, the inhibitory effect of quercetin on the growth of utilized cancer cell lines was dose- and time-dependent, as demonstrated by the obtained $\mathrm{IC}_{50}$ values of quercetin (Table II). It is noteworthy, based on our cancer cell line panel (Table II), that we selected cell lines of lower and higher sensitivity to quercetin.

Determination of the apoptosis of CT-26, LNCAP, MOLT-4 and Raji cell lines following treatment with quercetin. In continuation, we examined the apoptotic rate in a panel of 4 cell lines of high and low sensitivity to quercetin (i.e., CT-26 and LNCaP, as well as MOLT-4 and Raji, respectively). Our results revealed that quercetin initiated the apoptotic process in these cells in a dose-dependent manner (Fig. 2). The effect of quercetin at $120 \mu \mathrm{M}$ on the apoptotic rate of the CT-26, LNCaP, MOLT-4 and Raji cell lines in comparison to the control group $(\mathrm{P}<0.001)$ is depicted in Fig. 1. The results of MTT assay were compatible with the results of Annexin V/PI assay, as the cell lines with a higher sensitivity to quercetin exhibited a higher apoptotic rate $(\mathrm{P}<0.001$; Figs. 1 and 2$)$.

Effect of quercetin treatment on tumor volume. In continuation, we evaluated the in vivo effect of quercetin on CT-26 and MCF-7 tumors; these cells lines exhibited a relatively lower sensitivity to quercetin in in vitro experiments (Table II). Therefore, mice bearing CT-26 and MCF-7 tumors were treated with various concentrations of quercetin (50, 100 and $200 \mathrm{mg} / \mathrm{kg}$; i.p.) This approach revealed that the administration of quercetin significantly reduced the tumor volume at all 3 utilized doses on day 18 post-treatment for CT26 tumors and on day 20 post-treatment for MCF-7 tumors $(\mathrm{P}<0.001$; Fig. 3).

Animal survival rate. In vivo experiments demonstrated that the survival rate for mice bearing CT-26 and MCF-7 tumors that were treated with the two higher concentrations of quercetin (100 and $200 \mathrm{mg} / \mathrm{kg}$ ) was significantly higher compared to the control group $(\mathrm{P}<0.05$ and $\mathrm{P}<0.01$, respectively). No significant difference in the survival rate was evident between the group treated with quercetin at $50 \mathrm{mg} / \mathrm{kg}$ and the control group ( $\mathrm{P}>0.05$; Fig. 4). 
Table I. Data obtained from MTT assay on the cell viability of different cell lines treated with quercetin (10, 20 , 40 , 80 and $120 \mu \mathrm{M}$ ) for 24,48 and $72 \mathrm{~h}$.

A, Cells treated for $24 \mathrm{~h}$

\begin{tabular}{|c|c|c|c|c|c|}
\hline Cell line & $10 \mu \mathrm{M}$ & $20 \mu \mathrm{M}$ & $40 \mu \mathrm{M}$ & $80 \mu \mathrm{M}$ & $120 \mu \mathrm{M}$ \\
\hline CT-26 & $94.2 \pm 4.4$ & $83.5 \pm 3.7$ & $75.1 \pm 4.2$ & $65.8 \pm 5.5$ & $49.7 \pm 5.9$ \\
\hline LNCaP & $96.8 \pm 5.4$ & $90.3 \pm 4.6$ & $71.7 \pm 2.2$ & $61.5 \pm 3.4$ & $45.1 \pm 5.0$ \\
\hline PC3 & $96.4 \pm 5.0$ & $87.6 \pm 4.9$ & $80.1 \pm 4.6$ & $75 \pm 4.4$ & $73.2 \pm 4.1$ \\
\hline PC12 & $91.1 \pm 6.5$ & $84.5 \pm 6.0$ & $68.5 \pm 6.8$ & $57.1 \pm 6.3$ & $40.3 \pm 4.4$ \\
\hline MCF-7 & $94.8 \pm 6.1$ & $90.2 \pm 5.9$ & $77.5 \pm 5.1$ & $66.4 \pm 4.7$ & $47.1 \pm 4.2$ \\
\hline MOLT-4 & $88.6 \pm 3.6$ & $70.2 \pm 4.1$ & $57.5 \pm 4.0$ & $46 \pm 2.8$ & $42.8 \pm 3$ \\
\hline U266B1 & $95.1 \pm 4.9$ & $73.1 \pm 5$ & $53.8 \pm 4.6$ & $47.5 \pm 3.3$ & $33.8 \pm 4.7$ \\
\hline Raji & $85.6 \pm 4.1$ & $80.1 \pm 3.2$ & $68.1 \pm 2.8$ & $42.9 \pm 3.2$ & $29.4 \pm 4.6$ \\
\hline $\mathrm{CHO}$ & $97.7 \pm 5.2$ & $91.3 \pm 5.5$ & $74.4 \pm 4.1$ & $75.4 \pm 4.1$ & $70.5 \pm 5.2$ \\
\hline
\end{tabular}

$\mathrm{B}$, Cells treated for $48 \mathrm{~h}$

\begin{tabular}{llcccc}
\hline Cell line & $10 \mu \mathrm{M}$ & $20 \mu \mathrm{M}$ & $40 \mu \mathrm{M}$ & $80 \mu \mathrm{M}$ & $120 \mu \mathrm{M}$ \\
\hline CT-26 & $87.4 \pm 5.4$ & $77.7 \pm 5.9$ & $70.3 \pm 4.1$ & $61.5 \pm 3.2$ & $42.1 \pm 3$ \\
LNCaP & $91.5 \pm 6.3$ & $84.2 \pm 5.1$ & $66.6 \pm 5.7$ & $46.7 \pm 4.9$ & $38.5 \pm 3.8$ \\
PC3 & $89.9 \pm 3.6$ & $77.6 \pm 3.2$ & $70.7 \pm 2.8$ & $52.2 \pm 3.3$ & $28.5 \pm 3.4$ \\
PC12 & $94.4 \pm 5$ & $80.8 \pm 3.4$ & $62.5 \pm 4.6$ & $44.5 \pm 3.2$ & $30.7 \pm 3.8$ \\
MCF-7 & $81.3 \pm 4.1$ & $70.2 \pm 3.1$ & $55.5 \pm 3.4$ & $39.6 \pm 3.7$ & $25.2 \pm 2.1$ \\
MOLT-4 & $70.6 \pm 2.8$ & $52.5 \pm 2.6$ & $43.1 \pm 1.9$ & $33.3 \pm 2.5$ & $21.6 \pm 1.4$ \\
U266B1 & $68.5 \pm 2.3$ & $53.4 \pm 1.8$ & $37.2 \pm 2$ & $33.4 \pm 1.6$ & $20.4 \pm 2.1$ \\
Raji & $60.6 \pm 3.6$ & $49.5 \pm 2.3$ & $30.3 \pm 2.4$ & $26.4 \pm 2.3$ & $14.6 \pm 3.3$ \\
CHO & $97.4 \pm 4.4$ & $81.3 \pm 3.4$ & $64.6 \pm 2.8$ & $45.8 \pm 2.6$ & $21.9 \pm 3.5$ \\
\hline
\end{tabular}

C, Cells treated for $72 \mathrm{~h}$

\begin{tabular}{|c|c|c|c|c|c|}
\hline Cell line & $10 \mu \mathrm{M}$ & $20 \mu \mathrm{M}$ & $40 \mu \mathrm{M}$ & $80 \mu \mathrm{M}$ & $120 \mu \mathrm{M}$ \\
\hline CT-26 & $65.5 \pm 1.5$ & $55.8 \pm 1.9$ & $35.9 \pm 0.83$ & $29.7 \pm 1.1$ & $25 \pm 2.3$ \\
\hline LNCaP & $58.4 \pm 2.9$ & $51.4 \pm 2.6$ & $39 \pm 1.9$ & $36.1 \pm 2.2$ & $30.7 \pm 2$ \\
\hline PC3 & $61.7 \pm 2.1$ & $57.3 \pm 1.8$ & $46.9 \pm 1.4$ & $36.2 \pm 0.9$ & $31.5 \pm 3.7$ \\
\hline PC12 & $50.4 \pm 3.6$ & $47.2 \pm 2.6$ & $40.8 \pm 1.8$ & $31.9 \pm 2.3$ & $22.1 \pm 1.1$ \\
\hline MCF-7 & $51.6 \pm 3.2$ & $48.5 \pm 2.9$ & $35.7 \pm 2.5$ & $30.8 \pm 3$ & $19.1 \pm 1.4$ \\
\hline MOLT-4 & $11.5 \pm 0.5$ & $10.2 \pm 0.45$ & $10 \pm 0.37$ & $5.2 \pm 0.48$ & $2.1 \pm 0.9$ \\
\hline U266B1 & $15.9 \pm 0.8$ & $13.3 \pm 0.65$ & $4.8 \pm 0.72$ & $6.8 \pm 1.1$ & $5.5 \pm 0.38$ \\
\hline Raji & $5.5 \pm 0.4$ & $2.7 \pm 0.8$ & $1.3 \pm 0.25$ & $0.25 \pm 0.12$ & $0.18 \pm 0.09$ \\
\hline $\mathrm{CHO}$ & $57.8 \pm 3.9$ & $52.4 \pm 3.2$ & $39.2 \pm 2.7$ & $28.5 \pm 2.1$ & $20.7 \pm 3.7$ \\
\hline
\end{tabular}

TUNEL assay. At the end of the experiment (36 days following treatment), all surviving animals were sacrificed, and tumors from all animals were dissected and the poly-D-lysine-coated coverslips for TUNEL assay were positioned. An increase in the percentage of apoptotic cells in the treated as compared to the control groups was observed; however, it did not reach statistical significance ( $\mathrm{P}>0.05$; Fig. 5).

\section{Discussion}

In spite of many advances in cancer therapy, cancer is still one of the major causes of mortality worldwide. Natural products, particularly flavones found in the human diet, have been found to exert anti-proliferative and apoptosis-promoting effects against cancer cells $(60,61)$. The current study demonstrated 

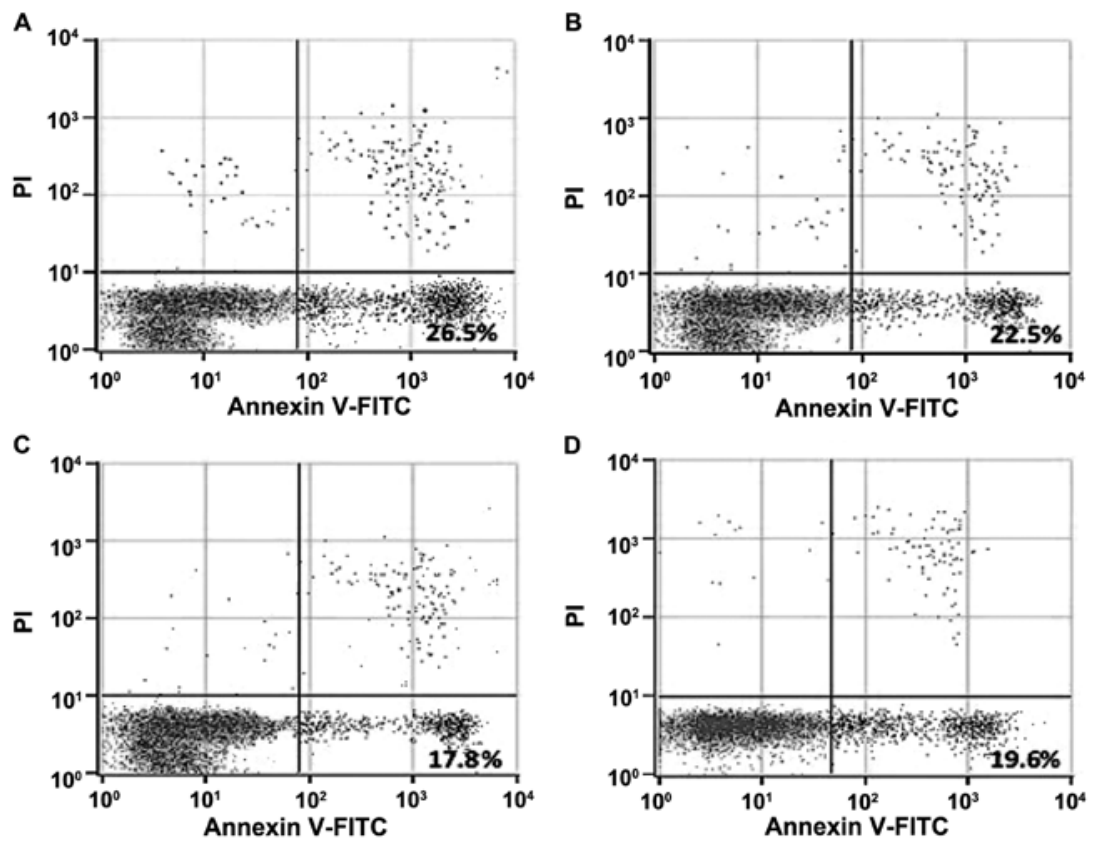

Figure 1. Apoptotic rate determined by Annexin V/PI staining in (A) CT-26, (B) LNCaP, (C) MOLT-4 and (D) Raji cell lines following 48 h of treatment with quercetin at $120 \mu \mathrm{M}$. Early apoptotic cells are Annexin V-positive and PI-negative (lower right quadrant). PI, propidium iodide.

Table II. $\mathrm{IC}_{50}$ values (in $\mu \mathrm{M}$ ) for the studied cell lines following treatment with various concentrations of quercetin $(10,20,40,80$, $120 \mu \mathrm{M}$ ) for 24,48 and $72 \mathrm{~h}$.

\begin{tabular}{lccr}
\hline Cell line & $24 \mathrm{~h}$ & \multicolumn{1}{c}{$48 \mathrm{~h}$} & \multicolumn{1}{c}{$72 \mathrm{~h}$} \\
\hline CT-26 & $118.1 \pm 5.55$ & $97.5 \pm 4.31$ & $27.2 \pm 1.52$ \\
LNCaP & $110.7 \pm 4.30$ & $72.6 \pm 5.15$ & $21.7 \pm 2.31$ \\
PC3 & $>120$ & $81.9 \pm 3.27$ & $36 \pm 1.98$ \\
PC12 & $99.3 \pm 6.11$ & $65.2 \pm 4$ & $11.8 \pm 2.27$ \\
MCF-7 & $105.4 \pm 5.2$ & $52.5 \pm 3.28$ & $13.7 \pm 2.61$ \\
MOLT-4 & $64.9 \pm 3.5$ & $28.6 \pm 2.23$ & $2.91 \pm 0.54$ \\
U266B1 & $54.3 \pm 4.5$ & $25 \pm 1.96$ & $6.13 \pm 0.73$ \\
Raji & $66.5 \pm 3.57$ & $19.2 \pm 2.83$ & $3.52 \pm 0.46$ \\
CHO & $>120$ & $70.7 \pm 3.44$ & $23.4 \pm 3.11$
\end{tabular}

$\mathrm{IC}_{50}$ values were calculated as previously described by Entezari Heravi et al (59).

that quercetin induces the apoptosis of various cancer cell lines. Furthermore, a significant increase in the survival rate and a significant reduction in tumor volume was observed in tumor-bearing animals treated with quercetin.

Previous studies have shown that grape stem extracts have an ability to inhibit the growth of colon (HT29), breast (MCF-7), renal (Caki-1) and thyroid (K1) cancer cell lines $(62,63)$. These extracts are rich in flavonols, particularly quercetin and rutin (63). Importantly, quercetin was found to be in both aglycon and glycoside forms (64). The inhibitory effect of quercetin on cancer cell growth is attributed to the inhibition of survival signaling proteins, such as protein kinase $\mathrm{C}(\mathrm{PKC}-\alpha)$ and the activation of death signals, such as PKC- $\delta(63)$. Moreover, grape

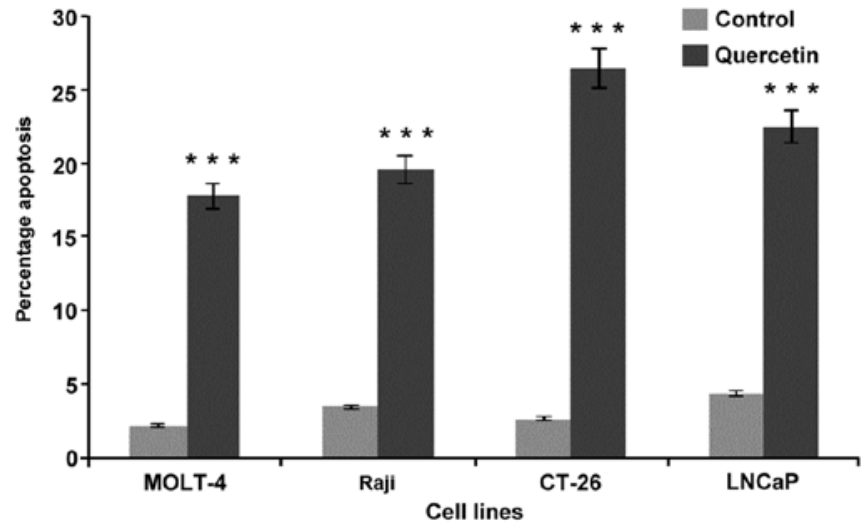

Figure 2. Induction of apoptosis in LNCaP, CT-26, MOLT-4 and Raji cell lines treated with quercetin as assessed by flow cytometer Annexin V/PI. The results revealed that quercetin significantly induced apoptosis in comparison to the control group $\left({ }^{* * * *} \mathrm{P}<0.001\right)$. PI, propidium iodide.

stem extracts seem to present an anti-angiogenic potential evident by VEGF downregulation (65).

Furthermore, quercetin induces pro-apoptotic effects via different mechanisms involving antioxidant effects and the suppression of $\mathrm{p} 53$ gene and BCL-2 protein (66). The suppression of BCL-2 gene transcription diminishes the inhibitory effects on BAD protein in the mitochondria, which is considered as the initiator of apoptosis for the intrinsic pathway (67).

The role of quercetin in apoptosis mediated by p53 has been studied in many cancer cell lines. When p53 is inhibited, cells become more susceptible toward cytotoxicity induced by quercetin (68). Apart from cell cycle regulation and the induction of apoptosis, p53 acts as a modulator of intracellular levels of ROS. In this regard, p53 exerts antioxidant effects in cells with no or low stress through the regulation of genes involved in such activity, which comprises microsomal GSH 

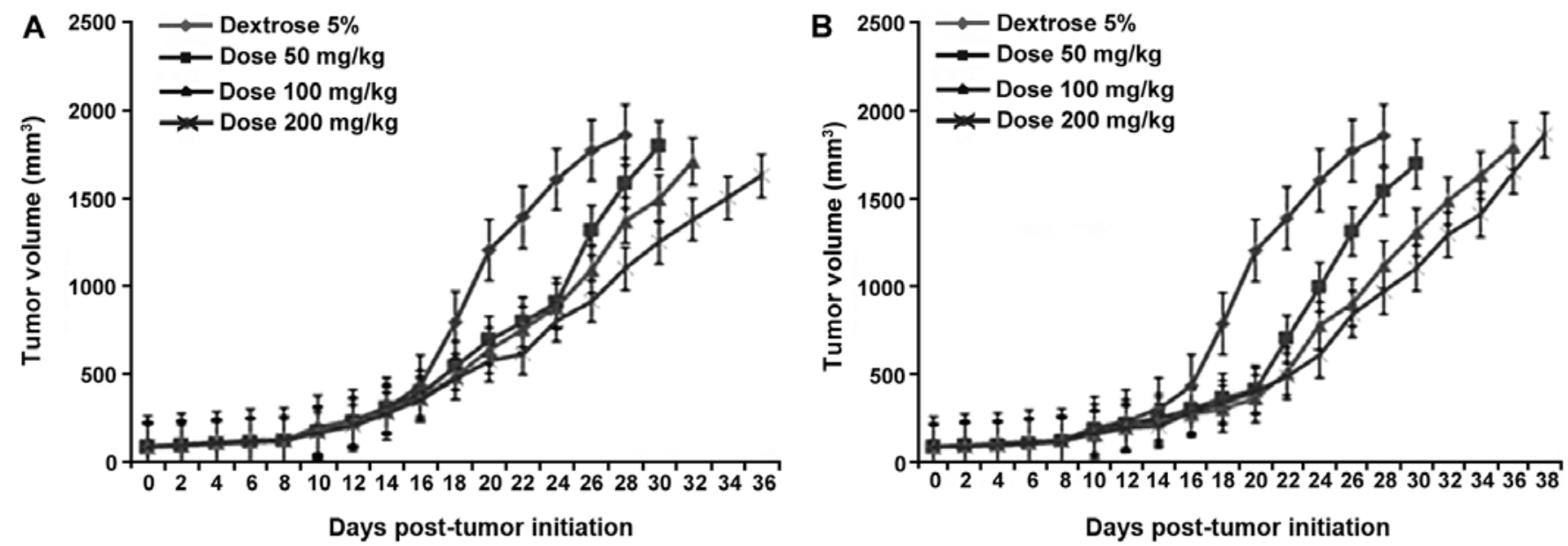

Figure 3. (A) In vivo tumor growth inhibition in BALB/c mice treated with various doses of quercetin (50,100 and $200 \mathrm{mg} / \mathrm{kg}$;intraperitoneally) inducted CT26 and (B) MCF-7 cell line. There were significant differences after 18 days of treatment between the quercetin-treated groups and the control group (dextrose 5\%). $\mathrm{P}<0.001$.

A

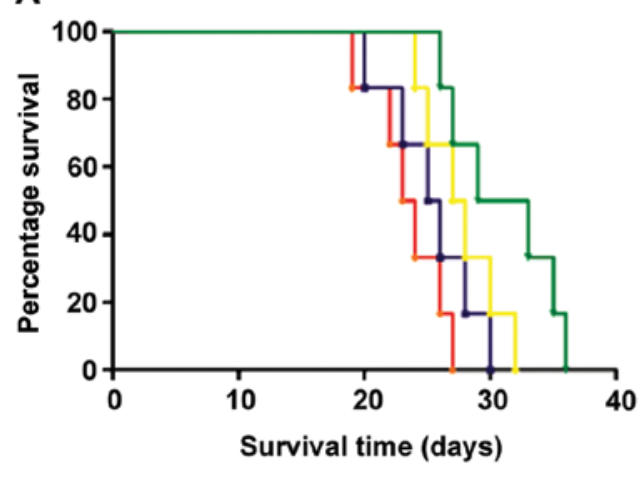

B

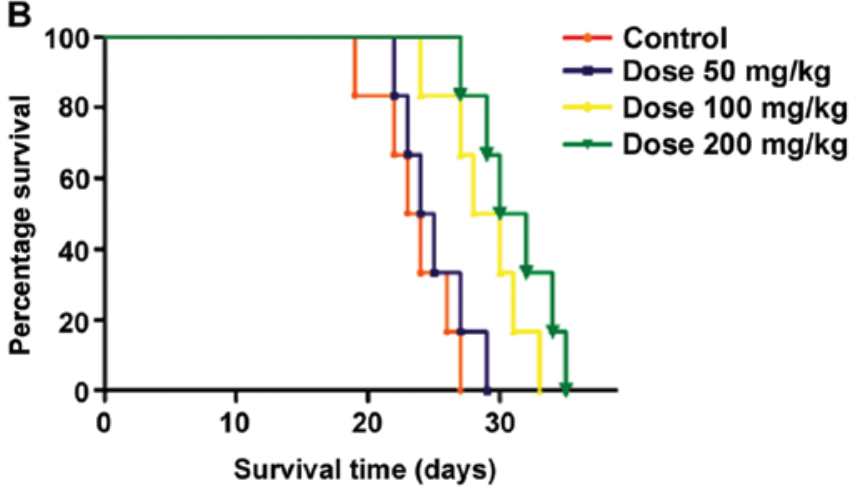

Figure 4. In vivo therapeutic efficacy of quercetin in BALB/c mice bearing (A) CT26 and (B) MCF-7 tumors following the intraperitoneal injection of quercetin at multiple doses $(50,100$ and $200 \mathrm{mg} / \mathrm{kg})$.

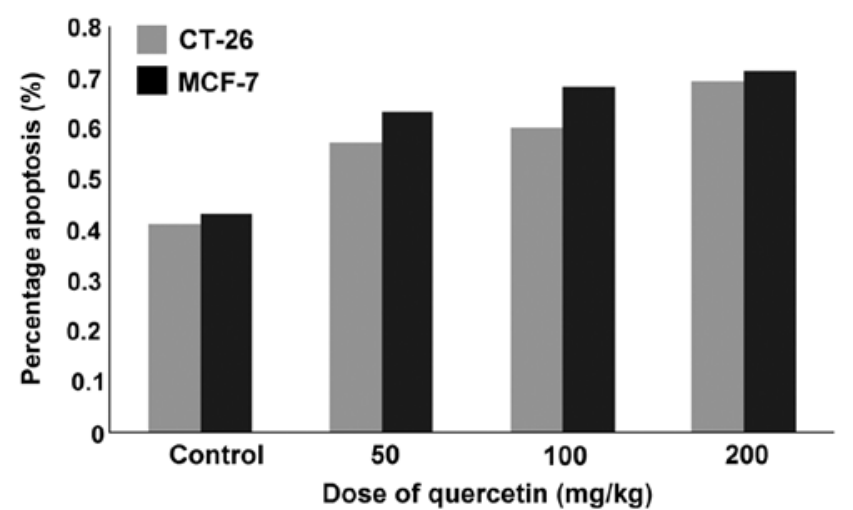

Figure 5. Percentage apoptosis in tumor slices from mice bearing CT-26 and MCF-7 tumors treatment with various concentration of quercetin $(50,100$ and $200 \mathrm{mg} / \mathrm{kg}$; intraperitoneally) as assessed by TUNEL assay.

transferase homolog PIG12 (69), aldehyde dehydrogenase 4 family member A1 (ALDH4A1) (70), Gpx1, manganese superoxide dismutase (SOD2) (71) and catalase (72). Some studies, however, have suggested that the effect of quercetin may be independent of p53. Although apoptotic cell death caused by DNA damage is often mediated by $\mathrm{p} 53$, there are other proteins, such as p63 and p73, which may be involved in this mechanism (73). Chien et al demonstrated that quercetin-induced apoptotic cell death was accompanied by a decrease in p53 expression in breast cancer cells (74). Additionally, quercetin inhibited the metabolic activity and induced cell death by apoptosis, followed by an increase in BAX expression with a concomitant decrease in the expression of anti-apoptotic proteins.

Quercetin has also been found to modulate the PI3K/Akt/mTOR pathway (75). The flavonoid has structural homology to the PI3K inhibitor, LY294002 (LY) and as expected, the phytochemical was found to inhibit the PI3K-Akt pathway in a similar manner to the inhibition elicited by LY in the breast cancer cell lines, HCC1937 and T47D (76). Breast cancer invasion was found to be suppressed by quercetin through the inactivation of the PKC/ERK/AP-1-dependent MMP-9 activation (76).

Quercetin exerts anticancer effects through the cell death domain mechanism at the cell surface (67). Quercetin activated the cell death domain which leads to FAS and FADD activation, and the induction of cell death in a cancer cell line via activation of caspase 8 (67). The above-mentioned findings are in accordance with the findings of the present study, which 
demonstrated the apoptotic-inducing properties of quercetin as assessed by the Annexin V/PI method.

The expression of heat shock proteins (HSPs) in almost all forms of cancer is elevated (58). Badziul et al showed that quercetin decreased the transcription and translation of HSP27 and 72 in the T98G cell line (58). HSPs are involved in cell proliferation and the inhibition of their production leads to cell apoptosis (77). This is well in accordance with our study, as we demonstrated that apoptosis was induced in quercetin-treated cancer cell lines. HSP27 has been reported to promote the development of leukemia by protecting tumor cells from apoptosis through various mechanisms. Another study investigated the effects of small hairpin (sh)RNA-mediated HSP27 knockdown on the anticancer effects of quercetin in U937 human leukemia cells. The results indicated that shHSP27 and quercetin synergistically inhibited U937 cell proliferation and induced apoptosis by reducing the $\mathrm{Bcl} 2 / \mathrm{Bax}$ ratio. Moreover, this combined treatment significantly suppressed the infiltration of tumor cells and the expression of the angiogenesis-associated proteins, hypoxia-inducible factor $1 \alpha$ (HIF $1 \alpha)$ and vascular endothelial growth factor (VEGF). In comparison with shHSP27 or quercetin separately, shHSP27 and quercetin together, notably decreased the expression of cyclin D1, and thus the cell cycle was arrested at the G1 phase (78). Furthermore, the Notch/AKT/mTOR signaling pathway contributes to tumor aggressiveness; quercetin plus shHSP27 has been shown to significantly decrease Notch 1 expression and the phosphorylation levels of the downstream signaling proteins, mTOR and AKT (79).

The anticancer effects of quercetin have been confirmed in many studies $(36,42,44)$. Specifically, in vitro and in vivo studies have suggested that quercetin possesses anticancer activity against different tumors; e.g. colon, lung, breast and prostate cancer (78,80-84). Quercetin can exert its anticancer effects through different mechanisms, including the inhibition of DNA topoisomerase I/II, the release of cytochrome $c$, the activation of caspase 3 , and HSP27 and 72 elevation $(37,58,85)$.

An in vivo examination of the effects of quercetin in mice bearing CT-26 tumors was performed for the first time in this study, at least to the best of our knowledge. The results revealed that quercetin significantly reduced the tumor volume and increased animal survival. Previous studies have provided evidence for the anticancer effects of quercetin on breast and prostate cancers in vivo $(86,87)$, an observation which was verified in the current study using the MCF-7 breast cancer in vivo model.

Importantly, quercetin can exert tumor suppressive effects by interfering with the cell cycle. The molecular targets of this flavonoid include p27, topoisomerase II, p21 and cyclin B $(88,89)$. Depending on the tumor origin, quercetin is able to block the cell cycle at G2/M or at the G1/S transition $(90,91)$. In breast cancer cell lines, a low dose of quercetin has been shown to induce mild DNA damage and Chk2 activation, which is the main regulator of p21 expression (92). In addition, quercetin has been shown to downregulate cyclin B1 and CDK1, essential components of G2/M cell cycle progression (92). Moreover, quercetin can inhibit the recruitment of NF-Y, a key transcription factor, which binds to the cyclin $\mathrm{B} 1$ gene promoter and leads to transcriptional cessation. In the human hepatoma cell line (HepG2), quercetin upregulated p21, p27 and p53, and consequently the cells were arrested at the G1 phase (93).
Furthermore, quercetin has been shown to inhibit $\mathrm{NF}-\kappa \mathrm{B}$-evoked pathways of cell survival and reduce pro-inflammatory cytokine expression that finally leads to cancer formation (94). Notably, quercetin inhibits the production of tumor necrosis factor (TNF)- $\alpha$, a major pro-inflammatory molecule involved in chronic inflammatory diseases, which may develop into tumors. The quercetin-induced suppression of TNF- $\alpha$ results in the stimulation of anti-inflammatory cytokines through the inhibition of NF- $\mathrm{BB}$ activation (95). TNF- $\alpha$ is a major regulator of the cellular release of other chemokines, cytokines and other inflammatory mediators, and thus can be considered as a potential target for the treatment of inflammatory diseases and inflammation-driven cancer. In the current study, quercetin was able to suppress tumor growth and improve animal survival (independent of its action on the induction of apoptosis).

Quercetin seems to play an inhibitory role in angiogenesis in human prostate tumor growth. A recent study using an animal model, indicated that low doses of quercetin inhibited the following angiogenic stages: proliferation and migration, as well as the invasion and tube formation of endothelial cells. Protein expression analysis of prostate cancer cells treated with quercetin revealed the inhibition of the VEGF-induced phosphorylation of VEGFR-2 and its downstream targets, such as mTOR, Akt, and ribosomal S6 kinase (86). Thus, quercetin can decrease tumor volume and increase animal survival rate following systemic administration, a finding which is consistent with the results of the present study.

The oral administration of quercetin is recommended for cancer prevention. It has been shown that a diet supplemented with $2 \%$ quercetin significantly reduced the onset of colorectal cancer (96). In addition, in vitro studies have proved its potency in inhibiting the proliferation of colon cancer cells of different lineages $(97,98)$. However, in a phase-1 clinical study performed at the University of Birmingham for the evaluation of the non-toxic and anticancer efficacy of quercetin in terminally ill cancer patients, no patient achieved conventional radiological response according to the WHO criteria, despite favorable indications of its anticancer activity (99).

In conclusion, our results demonstrate that quercetin inhibits the growth of a panel of 9 cancer cell lines with various $\mathrm{IC}_{50}$ values. Cell growth inhibition was attributed to the induction of apoptosis, evident in the CT-26, PC-12, LNCaP and $\mathrm{PC}-3$ cancer cell lines. Furthermore, our results demonstrated that quercetin reduced CT-26 and MCF-7 tumor volume in a mouse model and increased animal survival; however, we did not verify increased in situ apoptosis in the induced tumors. The current study results strongly suggest that quercetin has potential for therapeutic application in neoplasia; however, further studies are required to confirm these findings.

\section{Acknowledgements}

Special thanks to Zabol University of Medical Sciences for their financial support.

\section{References}

1. Schnekenburger M, Dicato M and Diederich M: Plant-derived epigenetic modulators for cancer treatment and prevention. Biotechnol Adv 32: 1123-1132, 2014. 
2. Butler MS, Robertson AA and Cooper MA: Natural product and natural product derived drugs in clinical trials. Nat Prod Rep 31: 1612-1661, 2014.

3. Hashemzaei M, Barani AK, Iranshahi M, Rezaee R, Tsarouhas K, Tsatsakis AM, Wilks MF and Tabrizian K: Effects of resveratrol on carbon monoxide-induced cardiotoxicity in rats. Environ Toxicol Pharmacol 46: 110-115, 2016.

4. Hashemzaei M, Entezari Heravi R, Rezaee R, Roohbakhsh A and Karimi G: Regulation of autophagy by some natural products as a potential therapeutic strategy for cardiovascular disorders. Eur J Pharmacol 802: 44-51, 2017.

5. DeVita VT Jr, Young RC and Canellos GP: Combination versus single agent chemotherapy: A review of the basis for selection of drug treatment of cancer. Cancer 35: 98-110, 1975.

6. Pisani P, Bray F and Parkin DM: Estimates of the world-wide prevalence of cancer for 25 sites in the adult population. Int J Cancer 97: 72-81, 2002.

7. Siegel R, Ward E, Brawley O and Jemal A: Cancer statistics, 2011: The impact of eliminating socioeconomic and racial disparities on premature cancer deaths. CA Cancer J Clin 61: 212-236, 2011

8. Ferlay J, Steliarova-Foucher E, Lortet-Tieulent J, Rosso S, Coebergh JW, Comber H, Forman D and Bray F: Cancer incidence and mortality patterns in Europe: Estimates for 40 countries in 2012. Eur J Cancer 49: 1374-1403, 2013.

9. Fridlender M, Kapulnik Y and Koltai H: Plant derived substances with anti-cancer activity: From folklore to practice. Front Plant Sci 6: 799, 2015.

10. Karikas GA: Anticancer and chemopreventing natural products: Some biochemical and therapeutic aspects. J BUON 15: 627-638, 2010.

11. Katz DL, Doughty K and Ali A: Cocoa and chocolate in human health and disease. Antioxid Redox Signal 15: 2779-2811, 2011.

12. Pandey KB and Rizvi SI: Current understanding of dietary polyphenols and their role in health and disease. Curr Nutr Food Sci 5: 249-263, 2009.

13. Pandey KB and Rizvi SI: Plant polyphenols as dietary antioxidants in human health and disease. Oxid Med Cell Longev 2: 270-278, 2009.

14. Kühnau J: The Flavonoids. A Class of Semi-Essential Food Components: Their Role in Human Nutrition. In: World Review of Nutrition and Dietetics. Bourne GH (ed). Karger, Basel, pp117-191, 1976

15. Scalbert A and Williamson G: Dietary intake and bioavailability of polyphenols. J Nutr 130 (Suppl): 2073S-2085S, 2000

16. Benbrook CM: Elevating Antioxidant Levels in Food through Organic Farming and Food Processing. An Organic Center, State of Science Review. The Organic Center for Education and Promotion, 2005.

17. Hashemzaei M, Karami SP, Delaramifar A, Sheidary A, Tabrizian K, Rezaee R, Shahsavand S, Arsene AL, Tsatsakis AM and Mohammad S: Anticancer effects of co-administration of daunorubicin and resveratrol in MOLT-4, U266 B1 and RAJI cell lines. Farmacia 64: 36-42, 2016.

18. Ramkissoon JS, Mahomoodally MF, Ahmed N and Subratty AH: Antioxidant and anti-glycation activities correlates with phenolic composition of tropical medicinal herbs. Asian Pac J Trop Med 6 : $561-569,2013$.

19. Glade MJ: Food, nutrition, and the prevention of cancer: a global perspective. American Institute for Cancer Research/World Cancer Research Fund, American Institute for Cancer Research, 1997. Nutrition 15: 523-526, 1999

20. Murillo G and Mehta RG: Cruciferous vegetables and cancer prevention. Nutr Cancer 41: 17-28, 2001.

21. Cronin FJ, Krebs-Smith SM, Wyse BW and Light L: Characterizing food usage by demographic variables. J Am Diet Assoc 81: 661-673, 1982

22. Block G, Dresser CM, Hartman AM and Carroll MD Nutrient sources in the American diet: quantitative data from the NHANES II survey. II. Macronutrients and fats. Am J Epidemiol 122: 27-40, 1985.

23. Hashemzaei M, SadeghiBonjar MA, Tabrizian K, Iranshahi M Iranshahy $M$ and Rezaee R: Evaluation of the analgesic effect of Umbelliprenin and Umbelliprenin-morphine co-administration on the acute, chronic and neuropathic pain. IJPER 49: 121-125, 2015.

24. Kumar S and Pandey AK: Chemistry and biological activities of flavonoids: An overview. Sci World J 2013: 162750, 2013.

25. Tabrizian K, Yaghoobi NS, Iranshahi M, Shahraki J, Rezaee R and Hashemzaei M: Auraptene consolidates memory, reverses scopolamine-disrupted memory in passive avoidance task, and ameliorates retention deficits in mice. Iran J Basic Med Sci 18: $1014-1019,2015$
26. Nikitovic D, Tsatsakis AM, Karamanos NK and Tzanakakis GN The effects of genistein on the synthesis and distribution of glycosaminoglycans/proteoglycans by two osteosarcoma cell lines depends on tyrosine kinase and the estrogen receptor density. Anticancer Res 23 (1A): 459-464, 2003.

27. Yamaguchi M, Murata T, El-Rayes BF and Shoji M: The flavonoid $p$-hydroxycinnamic acid exhibits anticancer effects in human pancreatic cancer MIA PaCa-2 cells in vitro: Comparison with gemcitabine. Oncol Rep 34: 3304-3310, 2015.

28. Cárdenas M, Marder M, Blank VC and Roguin LP: Antitumor activity of some natural flavonoids and synthetic derivatives on various human and murine cancer cell lines. Bioorg Med Chem 14: 2966-2971, 2006

29. Chan FL, Choi HL, Chen ZY, Chan PS and Huang Y: Induction of apoptosis in prostate cancer cell lines by a flavonoid, baicalin. Cancer Lett 160: 219-228, 2000.

30. Kawaii S, Tomono Y, Katase E, Ogawa K and Yano M: Antiproliferative activity of flavonoids on several cancer cell lines. Biosci Biotechnol Biochem 63: 896-899, 1999.

31. Lin P, Tian XH, Yi YS, Jiang WS, Zhou YJ and Cheng WJ: Luteolin-induced protection of $\mathrm{H}_{2} \mathrm{O}_{2}$-induced apoptosis in PC12 cells and the associated pathway. Mol Med Rep 12: 7699-7704, 2015.

32. Leung HW, Kuo CL, Yang WH, Lin CH and Lee HZ: Antioxidant enzymes activity involvement in luteolin-induced human lung squamous carcinoma $\mathrm{CH} 27$ cell apoptosis. Eur J Pharmacol 534: 12-18, 2006.

33. Wu TH, Yen FL, Lin LT, Tsai TR, Lin CC and Cham TM: Preparation, physicochemical characterization, and antioxidant effects of quercetin nanoparticles. Int J Pharm 346: 160-168, 2008.

34. Busch C, Burkard M, Leischner C, Lauer UM, Frank J and Venturelli S: Epigenetic activities of flavonoids in the prevention and treatment of cancer. Clin Epigenetics 7: 64, 2015.

35. Gilbert ER and Liu D: Flavonoids influence epigenetic-modifying enzyme activity: Structure - function relationships and the therapeutic potential for cancer. Curr Med Chem 17: 1756-1768, 2010

36. Erlund I: Review of the flavonoids quercetin, hesperetin, and naringenin. Dietary sources, bioactivities, bioavailability, and epidemiology. Nutr Res 24: 851-874, 2004.

37. Jakubowicz-Gil J, Paduch R, Piersiak T, Głowniak K, Gawron A and Kandefer-Szerszeń M: The effect of quercetin on pro-apoptotic activity of cisplatin in HeLa cells. Biochem Pharmacol 69: 1343-1350, 2005.

38. Ramos S: Effects of dietary flavonoids on apoptotic pathways related to cancer chemoprevention. J Nutr Biochem 18: 427-442, 2007.

39. Ren MX, Deng XH, Ai F, Yuan GY and Song HY: Effect of quercetin on the proliferation of the human ovarian cancer cell line SKOV-3 in vitro. Exp Ther Med 10: 579-583, 2015.

40. Deng XH, Song HY, Zhou YF, Yuan GY and Zheng FJ: Effects of quercetin on the proliferation of breast cancer cells and expression of survivin in vitro. Exp Ther Med 6: 1155-1158, 2013

41. Ren KW, Li YH, Wu G, Ren JZ, Lu HB, Li ZM and Han XW: Quercetin nanoparticles display antitumor activity via proliferation inhibition and apoptosis induction in liver cancer cells. Int J Oncol 50: 1299-1311, 2017.

42. Chen J and Kang JH: Quercetin and trichostatin A cooperatively kill human leukemia cells. Pharmazie 60: 856-860, 2005.

43. Priego S, Feddi F, Ferrer P, Mena S, Benlloch M, Ortega A, Carretero J, Obrador E, Asensi M and Estrela JM: Natural polyphenols facilitate elimination of HT-29 colorectal cancer xenografts by chemoradiotherapy: A Bcl-2- and superoxide dismutase 2-dependent mechanism. Mol Cancer Ther 7: 3330-3342, 2008

44. Scambia G, Ranelletti FO, Panici PB, De Vincenzo R, Bonanno G, Ferrandina G, Piantelli M, Bussa S, Rumi C, Cianfriglia M, et al: Quercetin potentiates the effect of adriamycin in a multidrug-resistant MCF-7 human breast-cancer cell line: P-glycoprotein as a possible target. Cancer Chemother Pharmacol 34: 459-464, 1994.

45. Yoshida M, Sakai T, Hosokawa N, Marui N, Matsumoto K, Fujioka A, Nishino H, and Aoike A: The effect of quercetin on cell cycle progression and growth of human gastric cancer cells. FEBS Lett 260: 10-13, 1990.

46. Sharma H, Sen S and Singh N: Molecular pathways in the chemosensitization of cisplatin by quercetin in human head and neck cancer. Cancer Biol Ther 4: 949-955, 2005.

47. Yang JH, Hsia TC, Kuo HM, Chao PD, Chou CC, Wei YH and Chung JG: Inhibition of lung cancer cell growth by quercetin glucuronides via G2/M arrest and induction of apoptosis. Drug Metab Dispos 34: 296-304, 2006. 
48. Gao X, Wang B, Wei X, Men K, Zheng F, Zhou Y, Zheng Y, Gou M, Huang M, Guo G, et al: Anticancer effect and mechanism of polymer micelle-encapsulated quercetin on ovarian cancer. Nanoscale 4: 7021-7030, 2012

49. Cao HH, Tse AK, Kwan HY, Yu H, Cheng CY, Su T, Fong WF and Yu ZL: Quercetin exerts anti-melanoma activities and inhibits STAT3 signaling. Biochem Pharmacol 87: 424-434, 2014.

50. Spagnuolo C, Russo M, Bilotto S, Tedesco I, Laratta B and Russo GL: Dietary polyphenols in cancer prevention: the example of the flavonoid quercetin in leukemia. Ann N Y Acad Sci 1259: 95-103, 2012.

51. Araújo JR, Gonçalves P and Martel F: Chemopreventive effect of dietary polyphenols in colorectal cancer cell lines. Nutr Res 31: 77-87, 2011.

52. Maira F, Catania A, Candido S, Russo AE, McCubrey JA, Libra M, Malaponte G and Fenga C: Molecular targeted therapy in melanoma: A way to reverse resistance to conventional drugs. Curr Drug Deliv 9: 17-29, 2012.

53. Castle JC, Loewer M, Boegel S, de Graaf J, Bender C, Tadmor AD, Boisguerin V, Bukur T, Sorn P, Paret C, et al: Immunomic genomic and transcriptomic characterization of CT26 colorectal carcinoma. BMC Genomics 15: 190, 2014.

54. Westerink RHS and Ewing AG: The PC12 cell as model for neurosecretion. Acta Physiol (Oxf) 192: 273-285, 2008.

55. Mayhew EG, Lasic D, Babbar S and Martin FJ: Pharmacokinetics and antitumor activity of epirubicin encapsulated in long-circulating liposomes incorporating a polyethylene glycol-derivatized phospholipid. Int J Cancer 51: 302-309, 1992.

56. Gao F, Li L, Liu T, Hao N, Liu H, Tan L, Li H, Huang X, Peng B Yan C, et al: Doxorubicin loaded silica nanorattles actively seek tumors with improved anti-tumor effects. Nanoscale 4 : 3365-3372, 2012

57. Tang L, Gabrielson NP, Uckun FM, Fan TM and Cheng J: Size-dependent tumor penetration and in vivo efficacy of monodisperse drug-silica nanoconjugates. Mol Pharm 10: 883-892, 2013.

58. Bądziul D, Jakubowicz-Gil J, Langner E, Rzeski W, Głowniak K and Gawron A: The effect of quercetin and imperatorin on programmed cell death induction in T98G cells in vitro. Pharmacol Rep 66: 292-300, 2014

59. Entezari Heravi R, Hadizadeh F, Sankian M, Tavakol Afshari J, Taghdisi SM, Jafarian H and Behravan J: Novel selective Cox-2 inhibitors induce apoptosis in Caco-2 colorectal carcinoma cell line. Eur J Pharm Sci 44: 479-86, 2011.

60. Chahar MK, Sharma N, Dobhal MP and Joshi YC: Flavonoids: A versatile source of anticancer drugs. Pharmacogn Rev 5: 1-12, 2011.

61. Batra P and Sharma AK: Anti-cancer potential of flavonoids: recent trends and future perspectives. 3 Biotech 3: 439-459, 2013

62. Apostolou A, Stagos D, Galitsiou E, Spyrou A, Haroutounian S Portesis N, Trizoglou I, Wallace Hayes A, Tsatsakis AM and Kouretas D: Assessment of polyphenolic content, antioxidant activity, protection against ROS-induced DNA damage and anticancer activity of Vitis vinifera stem extracts. Food Chem Toxicol 61: 60-68,2013.

63. Sahpazidou D, Geromichalos GD, Stagos D, Apostolou A, Haroutounian SA, Tsatsakis AM, Tzanakakis GN, Hayes AW and Kouretas D: Anticarcinogenic activity of polyphenolic extracts from grape stems against breast, colon, renal and thyroid cancer cells. Toxicol Lett 230: 218-224, 2014

64. Erlund I, Kosonen T, Alfthan G, Mäenpää J, Perttunen K, Kenraali J, Parantainen J and Aro A: Pharmacokinetics of quercetin from quercetin aglycone and rutin in healthy volunteers. Eur J Clin Pharmacol 56: 545-553, 2000

65. Stagos D, Apostolou A, Poulios E, Kermeliotou E, Mpatzilioti A, Kreatsouli K, Koulocheri SD, Haroutounian SA and Kouretas D: Antiangiogenic potential of grape stem extract through inhibition of vascular endothelial growth factor expression. J Physiol Pharmacol 65: 843-852, 2014.

66. Hsu CL and Yen GC: Phenolic compounds: Evidence for inhibitory effects against obesity and their underlying molecular signaling mechanisms. Mol Nutr Food Res 52: 53-61, 2008.

67. Vargas AJ and Burd R: Hormesis and synergy: Pathways and mechanisms of quercetin in cancer prevention and management Nutr Rev 68: 418-428, 2010.

68. Kuo P-C, Liu H-F and Chao J-I: Survivin and p53 modulate quercetin-induced cell growth inhibition and apoptosis in human lung carcinoma cells. J Biol Chem 279: 55875-55885, 2004.

69. Polyak K, Xia Y, Zweier JL, Kinzler KW and Vogelstein B: A model for p53-induced apoptosis. Nature 389: 300-305, 1997.
70. Yoon KA, Nakamura Y and Arakawa H: Identification of ALDH4 as a p53-inducible gene and its protective role in cellular stresses. J Hum Genet 49: 134-140, 2004.

71. Hussain SP, Amstad P, He P, Robles A, Lupold S, Kaneko I, Ichimiya M, Sengupta S, Mechanic L, Okamura S, et al: p53-induced up-regulation of MnSOD and GPx but not catalase increases oxidative stress and apoptosis. Cancer Res 64: 2350-2356, 2004.

72. O'Connor JC, Wallace DM, O'Brien CJ and Cotter TG: A novel antioxidant function for the tumor-suppressor gene p53 in the retinal ganglion cell. Invest Ophthalmol Vis Sci 49: 4237-4244, 2008.

73. Ozaki T and Nakagawara A: p73, a sophisticated p53 family member in the cancer world. Cancer Sci 96: 729-737, 2005.

74. Chien SY, Wu YC, Chung JG, Yang JS, Lu HF, Tsou MF, Wood WG, Kuo SJ and Chen DR: Quercetin-induced apoptosis acts through mitochondrial- and caspase-3-dependent pathways in human breast cancer MDA-MB-231 cells. Hum Exp Toxicol 28: 493-503, 2009.

75. Shen X, Si Y, Wang Z, Wang J, Guo Y and Zhang X: Quercetin inhibits the growth of human gastric cancer stem cells by inducing mitochondrial-dependent apoptosis through the inhibition of PI3K/Akt signaling. Int J Mol Med 38: 619-626, 2016.

76. Lin CW, Hou WC, Shen SC, Juan SH, Ko CH, Wang LM and Chen YC: Quercetin inhibition of tumor invasion via suppressing

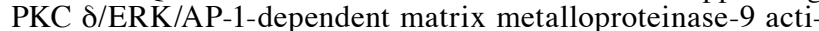
vation in breast carcinoma cells. Carcinogenesis 29: 1807-1815, 2008.

77. Lee C-H, Hong H-M, Chang Y-Y and Chang W-W: Inhibition of heat shock protein (Hsp) 27 potentiates the suppressive effect of Hsp90 inhibitors in targeting breast cancer stem-like cells. Biochimie 94: 1382-1389, 2012.

78. Catanzaro D, Ragazzi E, Vianello C,Caparrotta L and Montopoli M: Effect of quercetin on cell cycle and cyclin expression in ovarian carcinoma and osteosarcoma cell lines. Nat Prod Commun 10: $1365-1368,2015$

79. Chen X, Dong XS, Gao HY, Jiang YF, Jin YL, Chang YY, Chen LY and Wang JH: Suppression of HSP27 increases the anti tumor effects of quercetin in human leukemia U937 cells. Mol Med Rep 13: 689-696, 2016.

80. Neuhouser ML: Dietary flavonoids and cancer risk: Evidence from human population studies. Nutr Cancer 50: 1-7, 2004.

81. Li W, Liu M, Xu YF, Feng Y, Che JP, Wang GC, and Zheng JH: Combination of quercetin and hyperoside has anticancer effects on renal cancer cells through inhibition of oncogenic microRNA-27a. Oncol Rep 31: 117-124, 2014.

82. Moon JH, Eo SK, Lee JH and Park SY: Quercetin-induced autophagy flux enhances TRAIL-mediated tumor cell death. Oncol Rep 34: 375-381, 2015.

83. Seo HS, Ku JM, Choi HS, Choi YK, Woo JK, Kim M, Kim I, Na CH, Hur H, Jang $\mathrm{BH}$, et al: Quercetin induces caspase-dependent extrinsic apoptosis through inhibition of signal transducer and activator of transcription 3 signaling in HER2-overexpressing BT-474 breast cancer cells. Oncol Rep 36: 31-42, 2016.

84. Yang FQ, Liu M, Li W, Che JP, Wang GC and Zheng JH: Combination of quercetin and hyperoside inhibits prostate cancer cell growth and metastasis via regulation of microRNA21. Mol Med Rep 11: 1085-1092, 2015.

85. Kandaswami C, Lee LT, Lee PP, Hwang JJ, Ke FC, Huang YT and Lee MT: The antitumor activities of flavonoids. In Vivo 19: 895-909, 2005.

86. Pratheeshkumar P, Budhraja A, Son YO, Wang X, Zhang Z, Ding S, Wang L, Hitron A, Lee JC, Xu M, et al: Quercetin inhibits angiogenesis mediated human prostate tumor growth by targeting VEGFR- 2 regulated AKT/mTOR/P70S6K signaling pathways. PLoS One 7: e47516, 2012.

87. Steiner J, Davis J, McClellan J, Enos R, Carson J, Fayad R, Nagarkatti M, Nagarkatti P, Altomare D, Creek K, et al: Dose-dependent benefits of quercetin on tumorigenesis in the C3(1)/SV40Tag transgenic mouse model of breast cancer. Cancer Biol Ther 15: 1456-1467, 2014.

88. Prasad S, Phromnoi K, Yadav VR, Chaturvedi MM and Aggarwal BB: Targeting inflammatory pathways by flavonoids for prevention and treatment of cancer. Planta Med 76: 1044-1063, 2010.

89. Yang H, Landis-Piwowar KR, Chen D, Milacic V and Dou QP: Natural compounds with proteasome inhibitory activity for cancer prevention and treatment. Curr Protein Pept Sci 9: 227-239, 2008 
90. Gibellini L, Pinti M, Nasi M, Montagna JP, De Biasi S, Roat E, Bertoncelli L, Cooper EL and Cossarizza A: Quercetin and cancer chemoprevention. Evid Based Complement Alternat Med 2011: 591356, 2011.

91. Zhou J, Fang L, Yao WX, Zhao X, Wei Y, Zhou H, Xie H, Wang LY and Chen LJ: Effect of quercetin on heat shock protein expression in HepG2 cells determined by SILAC. Zhonghua Zhong Liu Za Zhi 33: 737-741, 2011 (In Chinese).

92. Jeong JH, An JY, Kwon YT, Rhee JG and Lee YJ: Effects of low dose quercetin: Cancer cell-specific inhibition of cell cycle progression. J Cell Biochem 106: 73-82, 2009.

93. Mu C, Jia P, Yan Z, Liu X, Li X and Liu H: Quercetin induces cell cycle G1 arrest through elevating Cdk inhibitors p21 and p27 in human hepatoma cell line (HepG2). Methods Find Exp Clin Pharmacol 29: 179-183, 2007.

94. Crespo I, García-Mediavilla MV, Gutiérrez B, Sánchez-Campos S, Tuñón MJ and González-Gallego J: A comparison of the effects of kaempferol and quercetin on cytokine-induced pro-inflammatory status of cultured human endothelial cells. Br J Nutr 100: 968-976, 2008

95. Nair MP, Mahajan S, Reynolds JL, Aalinkeel R, Nair H, Schwartz SA and Kandaswami C: The flavonoid quercetin inhibits proinflammatory cytokine (tumor necrosis factor alpha) gene expression in normal peripheral blood mononuclear cells via modulation of the NF-kappa beta system. Clin Vaccine Immunol 13: 319-328, 2006.
96. Matsukawa Y, Nishino H, Okuyama Y, Matsui T, Matsumoto T, Matsumura S, Shimizu Y, Sowa Y and Sakai T: Effects of quercetin and/or restraint stress on formation of aberrant crypt foci induced by azoxymethane in rat colons. Oncology 54: 118-121, 1997.

97. Shan BE, Wang MX and Li RQ: Quercetin inhibit human SW480 colon cancer growth in association with inhibition of cyclin D1 and survivin expression through Wnt/beta-catenin signaling pathway. Cancer Invest 27: 604-612, 2009.

98. Yang K, Lamprecht SA, Liu Y, Shinozaki H, Fan K, Leung D, Newmark H,Steele VE,Kelloff GJ and Lipkin M: Chemoprevention studies of the flavonoids quercetin and rutin in normal and azoxymethane-treated mouse colon. Carcinogenesis 21: 1655-1660, 2000.

99. Ferry DR, Smith A, Malkhandi J, Fyfe DW, deTakats PG, Anderson D, Baker J and Kerr DJ: Phase I clinical trial of the flavonoid quercetin: Pharmacokinetics and evidence for in vivo tyrosine kinase inhibition. Clin Cancer Res 2: 659-668, 1996. 